\title{
Multi-objective optimization in WEDM of D3 tool steel using integrated approach of Taguchi method \& Grey relational analysis
}

\author{
Anand S. Shivade $\cdot$ Vasudev D. Shinde
}

Received: 31 March 2014/Accepted: 22 July 2014/Published online: 11 September 2014

(C) The Author(s) 2014. This article is published with open access at Springerlink.com

\begin{abstract}
In this paper, wire electrical discharge machining of D3 tool steel is studied. Influence of pulse-on time, pulse-off time, peak current and wire speed are investigated for MRR, dimensional deviation, gap current and machining time, during intricate machining of $\mathrm{D} 3$ tool steel. Taguchi method is used for single characteristics optimization and to optimize all four process parameters simultaneously, Grey relational analysis (GRA) is employed along with Taguchi method. Through GRA, grey relational grade is used as a performance index to determine the optimal setting of process parameters for multiobjective characteristics. Analysis of variance (ANOVA) shows that the peak current is the most significant parameters affecting on multi-objective characteristics. Confirmatory results, proves the potential of GRA to optimize process parameters successfully for multi-objective characteristics.
\end{abstract}

Keywords ANOVA - D3 tool steel - Grey relational analysis - Multi-objective optimization - Taguchi method · Wire electrical discharge machining (WEDM)

\section{Introduction}

The wire electric discharge machining (WEDM) process contributes a predominant role in some manufacturing sectors recently; since this process has the capacity to cut complex and intricate shapes of components in all electrically conductive materials with better precision and

A. S. Shivade $(\bowtie) \cdot$ V. D. Shinde

DKTEs, Textile and Engineering Institute, Ichalkaranji,

Kolhapur, Maharashtra, India

e-mail: shivadeanand@yahoo.in accuracy. In the WEDM process there is no relative contact between the tool and work material, therefore the work material hardness is not a limiting factor for machining materials by this process. In this operation, the material removal occurs from any electrically conductive material by the initiation of rapid and repetitive spark discharges between the gap of the work and tool electrode connected in an electrical circuit, and the liquid dielectric medium is continuously supplied to deliver the eroded particles and to provide the cooling effect. A small diameter wire ranging from 0.05 to $0.3 \mathrm{~mm}$ (Rao 2011) is applied as the tool electrode. The wire is continuously supplied from the supply spool (Fig. 1), through the work-piece, which is clamped on the table by the wire traction rollers. A gap of $0.025-0.05 \mathrm{~mm}$ is maintained constantly between the wire and work-piece. De-ionized water is applied as the dielectric fluid. A collection tank that is located at the bottom is used to collect the used wire and then discard it. The wires once used cannot be reused again due to the variation in dimensional accuracy. The dielectric fluid is continuously flashed through the gap along the wire, to the sparking area to remove the by products formed during the erosion (Kalpakjian and Schmid 2009). Nowadays WEDM is an important machine tool to produce complex and intricate shapes of components in areas such as tool and die making industries, automobile, aerospace, nuclear, computer and electronics industries.

\section{Literature review}

Every machining process deals with Single characteristics and/or Multi-objective characteristics, which may be equally important and affect the product quality and economy. Numbers of different techniques such as Taguchi 


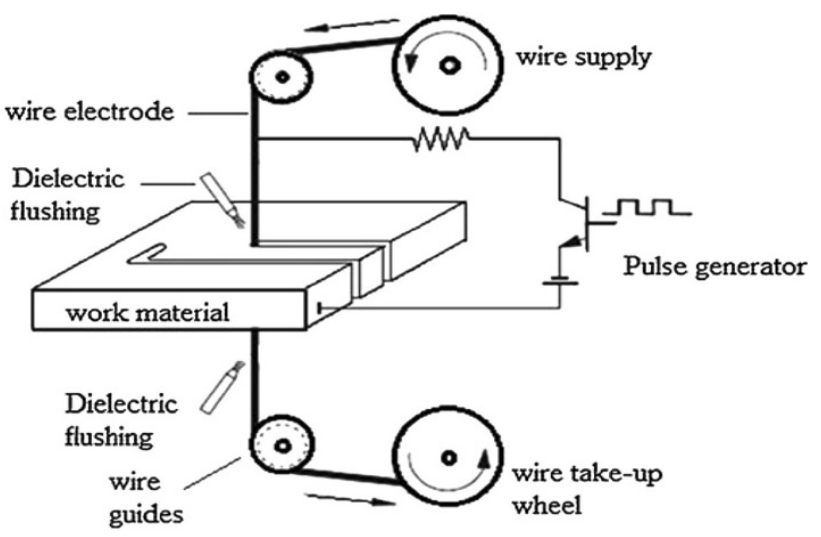

Fig. 1 Representation of WEDM process

robust design method, Factorial design method, Statistical regression analysis, GRA, principle component analysis, Response surface methodology, utility theory, etc., are available to optimize the Single and multi-objective characteristics optimization. Several authors have successfully employed different optimization techniques to improve the process performance.

Tosun (2003) modelled the variation of response variables with the machining parameters of a WEDM process using regression analysis method, and then applied simulated annealing based searching for determination of the machining parameters that can simultaneously optimize all the performance measures. Liao et al. (1997) established mathematical models relating the machining performances with various machining parameters, and then determined the optimal parametric settings for the WEDM processes using feasible-direction method of non-linear programining. Ahmad et al. (2001) studied machinability of aluminum matrix composite (AMC). The full factorial design of experimental approach with two levels were used to determine the combination of machining parameter based on pulse-off time, servo voltage and wire tension. They concluded that the servo voltages have significant influence on the MRR. Mahapatra and Patnaik (2006) established the relationship between various process parameters and responses using non-linear regression analysis and then employed genetic algorithm to optimize the WEDM process. Singh and Garg (2009) machined hot die steel (H-11) on WEDM. They studied the effects of process parameters on MRR using one variable at a time approach. Finally conclude that by increasing the pulse on time the MRR also increases and vice versa. Jangra et al. (2011) investigated the Influence of taper angle, peak current, pulse-on time, pulse-off time, wire tension and dielectric flow rate for MRR and surface roughness during machining of WC-Co composite. In order to optimize MRR and surface roughness GRA is used along with Taguchi method. Durairaj et al. (2013) examined the effect of process parameters on surface roughness and kerf width on WEDM using SS304. For experimentation Taguchi L16 OA has been used. By using multi-objective optimization technique GRA theory, the optimal value is obtained for surface roughness and kerf width and by using Taguchi optimization technique, optimized value is obtained separately. Shivade and Shinde (2013) proposed different approaches which may also be quite useful for multi-objective optimization of WEDM processes. Chiang and Chang (2006) optimized the surface roughness and MRR of a WEDM process for $\mathrm{Al}_{2} \mathrm{O}_{3}$ particle reinforced material based on GRA method. Ramakrishna and Karunamoorthy (2006) used multi-objective optimization method using Taguchi's robust design approach for WEDM. Each experiment had been performed under different cutting conditions of pulse on time, wire tension, delay time, wire feed speed and ignition current intensity. Three responses, namely MRR, surface roughness and wire wear ratio had been considered. It was observed that the Taguchi's parameter design is a simple, systematic, reliable and more efficient tool for optimization of the machining parameters. It was identified that the pulse on time and ignition current had influenced more than the other parameters. Sarkar et al. (2005) presented an approach to select the optimum cutting condition with an appropriate wire offset setting in order to get the desired surface roughness and dimensional accuracy for machining of $\gamma$-titanium aluminide alloy. The process has been modeled using additive model in order to predict the response parameters, i.e., cutting speed, surface roughness and dimensional deviation. Muthu et al. (2011) investigated experimentally the influence of the machining parameter on the kerf width, metal removal rate and the surface roughness of the machined workpiece surface using Taguchi method. Jangra et al. (2012) proposed integrated approach for multi-objective optimization for WC$5.3 \%$ Co composite on WEDM using Taguchi, GRA and entropy method. Hewidy et al. (2005) developed a mathematical model based on response surface methodology for correlating the relationships of various WEDM parameters of Inconel 601 material such as peak current, duty factor, wire tension and water pressure on the MRR, wear ratio and surface roughness. Rao and Pawar (2009) highlighted the development of mathematical models using response surface modeling for correlating the relationships of various WEDM parameters such as pulse on-time, pulse offtime, peak current, and servo feed setting on the machining speed and surface roughness. ABC algorithm was then applied to find the optimal combination of process parameters with an objective of achieving maximum machining speed for a desired value of surface finish. Datta and Mahapatra (2010) derived a quadratic mathematical model to represent the process behavior of WEDM operation. Experiments have been conducted with six process 
parameters: discharge current, pulse duration, pulse frequency, wire speed, wire tension and dielectric flow rate; to be varied in three different levels. Process responses such as Material Removal Rate, surface finish and kerf have been measured. These data have been utilized to fit a quadratic mathematical model (response surface model) for each of the responses.GRA has been adopted to convert this multi-objective criterion into an equivalent single objective function; Optimal setting has been verified through confirmatory test; showed good agreement to the predicted value. Kumar et al. (2013) investigated effect of various WEDM parameters on four response variables, i.e., machining rate, surface roughness, dimensional deviation and wire wear ratio on pure titanium (Grade-2) using RSM. The experimental plan is based on Box-Behnken design. The six parameters, i.e., pulse on time, pulse off time, peak current, spark gap voltage, wire feed and wire tension have been varied to investigate their effect on output responses. The ANOVA has been applied to identify the significance of developed model. Shandilya et al. (2011) used a RSM and artificial neural network based mathematical modeling for average cutting speed of $\mathrm{SiC}_{\mathrm{p}} / 6061 \mathrm{Al}$ metal matrix composite during WEDM. Four WEDM parameters namely servo voltage, pulse-on time, pulse-off time and wire feed rate were chosen as machining process parameters. They developed a back propagation neural network to establish the process model. The performance of the developed artificial neural network models was compared with the RSM mathematical models of average cutting speed. Sharma et al. (2013) investigated the effect of parameters on metal removal rate for WEDM using high strength low alloy as work-piece and brass wire as electrode. They observed that material removal rate and surface roughness increase with increase in pulse on time and peak current. RSM is used to optimize the process parameter for Material removal rate and surface roughness. They developed a mathematical model which correlates the independent process parameters with the desired metal removal rate and Surface Roughness. The central composite rotatable design has been used to conduct the experiments.

Most of the researchers used response surface method for multi-objective optimization. In modeling and optimization of manufacturing processes using RSM, the sufficient data is collected through designed experimentation. In general, a second-order regression model is developed because first-order models often give lack-of-fit, on the other hand, the major drawback of RSM is to fit the data to a second-order polynomial. It cannot be said that all systems containing curvature are well accommodated by the second-order polynomial (Rao 2011). To overcome this, the data can be converted into another form that can be explained by the second-order model; this disadvantage is overcome in other multi-objective method like GRA. This is an impacting measurement method in grey system theory that analyzes uncertain relations between one main factor and all the other factors in a given system. In the case when experiments are ambiguous or when the experimental method cannot be carried out exactly, grey analysis helps to compensate for the shortcomings in statistical regression. GRA is actually a measurement of the absolute value of the data difference between sequences, and it could be used to measure the approximate correlation between sequences (Tosun 2006).

\section{Experimental works}

In this study, Taguchi method is used for single characteristics optimization and GRA has been used to establish correlation between the independent variables and the multi-objective characteristics; therefore, the experiments were performed according to a Taguchi design of experiments.

Work material and cutting tool (electrode)

The work material selected in this investigation was AISI D3 tool steel. The chemical composition of the D3 tool steel includes: $\mathrm{C}, 2.25 ; \mathrm{Si}, 0.60, \mathrm{Mn}, 0.60 ; \mathrm{Cr}, 12 ; \mathrm{Ni}, 0.30 ; \mathrm{W}, 1$; $\mathrm{V}, 1 ; \mathrm{Cu} 0.25 ; \mathrm{P}, 0.03 ; \mathrm{S}, 0.03$. A Commercially available D3 plate with $30 \mathrm{~mm}$ thickness was used to prepare $20 \times 20 \mathrm{~mm}$ Square shaped specimens for performing WEDM experiments. A commercially available Molybdenum wire of diameter 0.18 is used as electrodes material.

\section{Design of experiments}

In present work, four different input process parameters and four performance measure selected which are discussed in following section.

\section{Input process parameters}

Pulse on time The pulse on time is referred as $T_{\text {on }}$ and it represents the duration of time in micro seconds ( $\mu \mathrm{s})$, for which the current is flowing in each cycle. During this time, the gap voltage is applied across the electrodes. The single pulse discharge energy increases with increasing $T_{\text {on }}$ period, resulting in higher cutting rate. With higher values of $T_{\mathrm{on}}$, however, surface roughness tends to be higher. The higher value of discharge energy may also cause wire breakage.

Pulse off time The pulse off time is referred as $\mathrm{T}_{\text {off }}$ and it represents the duration of time in micro seconds $(\mu \mathrm{s})$, between the two simultaneous sparks. The voltage is absent during this part of the cycle. With a lower value of $T_{\text {off }}$, 
there is more number of discharges in a given time, resulting in increase in the sparking efficiency. As a result, the cutting rate also increases. Using very low values of $T_{\text {off }}$ period, however, may cause wire breakage which in turn reduces the cutting efficiency. As and when the discharge conditions become unstable, one can increase the $T_{\text {off }}$ period. This will allow lower pulse duty factor and will reduce the average gap current.

Peak current The peak current $\left(I_{\mathrm{p}}\right)$ is the maximum value of the current passing through the electrodes for the given pulse. Increase in the $I_{P}$ value will increase the pulse discharge energy which in turns improves the cutting rate further. For higher value of $I_{\mathrm{p}}$, gap conditions may become unstable with improper combination of $T_{\mathrm{on}}, T_{\mathrm{off}}$ or other parameter settings. As and when the discharge conditions become unstable one must reduce the $I_{\mathrm{p}}$ value.

Wire speed Wire speed is the speed at which the wire electrode travels along the wire guide path and is fed continuously for sparking. In WEDM, wire electrode contributes $70 \%$ of the machining cost. Therefore, it is desirable to set proper wire feed rate for stable machining with no or less wire breakage occurs.

\section{Output process parameters}

Material removal rate (MRR) For WEDM, MRR is a desirable characteristic and it should be as high as possible to increase the productivity and also estimation of the total cost of the machined area depends on it. MRR can be expressed in $\mathrm{mm} / \mathrm{min}$ or $\mathrm{mm}^{2} / \mathrm{min}$. Cutting speed (Cs) was observed from machine tool monitor screen which gives linear cutting speed in terms of $\mathrm{mm} / \mathrm{min}$, therefore, MRR for the WEDM operation can be calculated using Eq. 1.

$\mathrm{MRR}=\mathrm{Cs} \times L$

where,

$$
\begin{aligned}
& \text { MRR = material removal rate. } \\
& \mathrm{Cs}=\text { cutting speed in } \mathrm{mm} / \mathrm{min} \text {. } \\
& \mathrm{L}=\text { thickness of the material in } \mathrm{mm} \text {. }
\end{aligned}
$$

Dimensional deviation In WEDM process, profile traced by the wire and the job profile are not same. The perpendicular distance between the actual profile and the profile traced by the wire is equal to half of the width of the cut as seen from Fig. 2. Thus the actual job produced by WEDM is either undersized or oversized depending upon whether the job is punch or die. This deviation in dimension is equal to the half the width of the cut. The effective way to solve this aspect is to shift the wire during cutting by an amount which is equal to dimensional deviation. This amount and

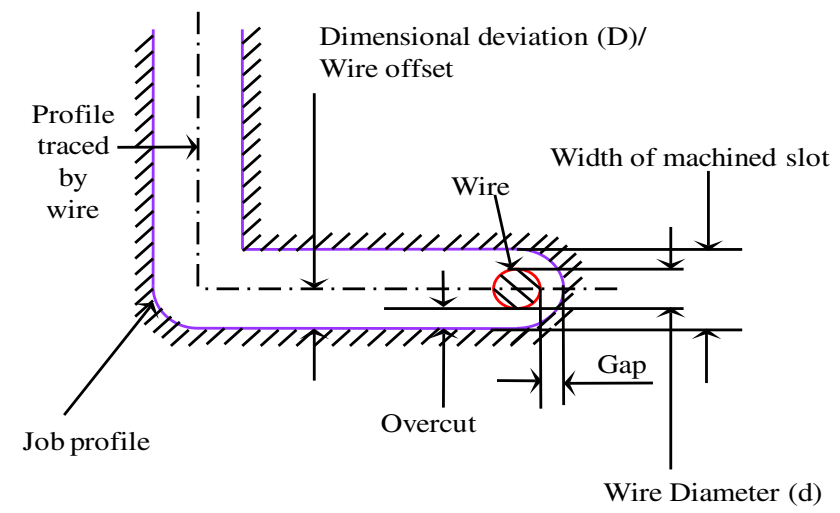

Fig. 2 Slot produces by the wire in WEDM

direction of shift of the wire can be controlled through part programming. This shift of wire through part programming is commonly termed as wire compensation or wire offset. Hence, in case of rough cutting, to eliminate dimensional deviation or dimensional inaccuracy, this wire offset setting $(\zeta)$ must be equal to dimensional deviation $(D)$. The orientation of this wire offset (i.e., left or right with respect to the programmed path) depends upon the direction (clockwise or counter clockwise) of cutting and type of job (i.e., die or punch). It may be noted that though the magnitude of dimensional deviation and wire offset are equal but their usage is kept different. The term "dimensional deviation" has been used as response parameter during cutting experiment in WEDM with zero wire offset. But, "wire offset" is a control setting in WEDM part programming to eliminate or minimize dimensional inaccuracy during actual machining.

Gap current In wire cut electric discharge machine, specimen is mounted on the machine and during the process of cutting, a small amount of gap is maintained between the job and the electrode wire as shown in Fig. 2 . To initiate the cutting a pulse of current is generated by the pulse generator in order to start the cutting process and the current that passes through the material is measured and named as gap current. The gap current is read on an ammeter, which is an integral part of the machine, in ampere.

Machining time It is the actual time required for cutting complete path on work piece in wire cut electric discharge machine and generally expressed in minutes or in seconds. Machining time is an important parameter for any process for deciding cost of product.

Experiments were designed using Taguchi method which uses an OA to study the entire parametric space with a limited number of experiments. In present research, four process parameters (factors) were chosen such as pulse on 
Table 1 Level values of input parameters

\begin{tabular}{llllll}
\hline Sr. no. & Parameters & Unit & Level 1 & Level 2 & Level 3 \\
\hline 1 & Pulse on time $\left(T_{\text {on }}\right)$ & $\mu \mathrm{s}$ & 3 & 6 & 9 \\
2 & Pulse off time $\left(T_{\text {off }}\right)$ & $\mu \mathrm{s}$ & 2 & 4 & 6 \\
3 & Peak current $\left(I_{\mathrm{P}}\right)$ & Amp & 1 & 2 & 3 \\
4 & Wire speed $(\mathrm{Ws})$ & $\mathrm{m} / \mathrm{min}$ & 3 & 5 & 7 \\
\hline
\end{tabular}

Table 2 L9 design matrix

\begin{tabular}{lllll}
\hline Expt. no. & Para. 1 & Para. 2 & Para. 3 & Para. 4 \\
\hline E 1 & 3 & 2 & 1 & 3 \\
E 2 & 3 & 4 & 2 & 5 \\
E 3 & 3 & 6 & 3 & 7 \\
E 4 & 6 & 2 & 2 & 7 \\
E 5 & 6 & 4 & 3 & 3 \\
E 6 & 6 & 6 & 1 & 5 \\
E 7 & 9 & 2 & 3 & 5 \\
E 8 & 9 & 4 & 1 & 7 \\
E 9 & 9 & 6 & 2 & 3 \\
\hline
\end{tabular}

time, pulse off time, peak current and wire speed. All of them were set at three different levels (Table 1).

Selection of a particular OA is based on the number of levels of various factors. Here, four parameters each at 3 levels, therefore Degree of Freedom (DOF) can be calculated as, Eq. 2

$(\mathrm{DOF}) \mathrm{R}=\mathrm{P}(\mathrm{L}-1)$

$\mathrm{P}=$ number of factors, $\mathrm{L}=$ number of levels

$(\mathrm{DOF}) \mathrm{R}=4 \times(3-1)=8$

Total DOF of OA should be greater than or equal to the total DOF required for the experiment (Phadke 2012), here $9>8$ hence L9 $\left(3^{4}\right)$ OA is selected (Table 2). Each machining parameter is assigned to a column of OA and 9 machining parameter combinations are designed. The response variables chosen for the present investigation are: MRR, Dimensional deviation, gap current and machining time. The "higher-the-better" quality characteristic has been used for calculating the signal to noise $(\mathrm{S} / \mathrm{N})$ ratio of MRR and Gap current, whereas "lower-the-better" quality characteristic for dimensional deviation and machining time. See Eq. (3 and 4) (Taguchi et al. 2005).

$$
\begin{aligned}
& \operatorname{MSD}_{\mathrm{HB}}=\frac{1}{R} \sum_{J=1}^{R}\left(\frac{1}{Y_{J}^{2}}\right) \\
& \mathrm{MSD}_{\mathrm{LB}}=\frac{1}{R} \sum_{J=1}^{R}\left(Y_{J}^{2}\right)
\end{aligned}
$$

where $y_{j}$ is the response value for $i$ th experiment

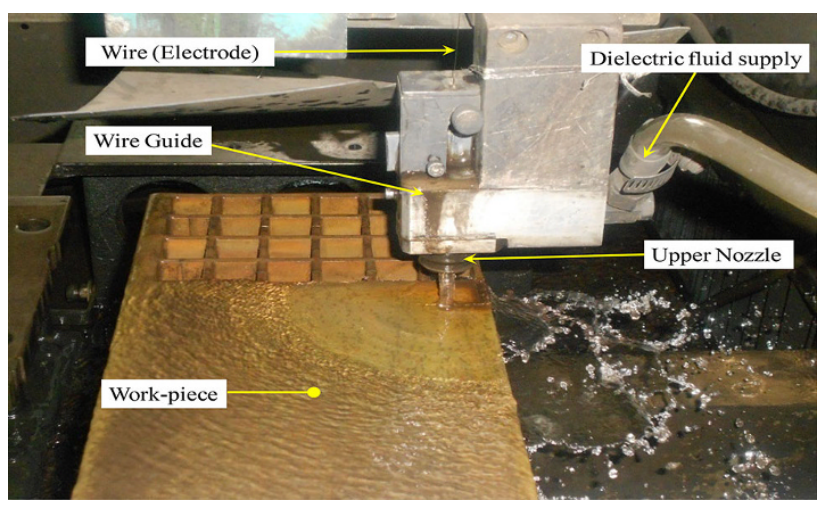

Fig. 3 Experimental set-up

Experimental planning

Experiments were conducted using an ELCTRONICA ELCUT CNC WEDM as per L9 OA combinations and each experiment were repeated three times for getting reliable database i.e., $9 \times 3$ total 27 experiments conducted. Fig. 3 shows the experimental setup for present study. Cutting speed and performance characteristics Gap current displayed on control panel and using cutting speed, MRR is calculated, also machining time measured using stopwatch and dimensional deviation measured using Mitutoyo made digital micrometer having Least count of $0.001 \mathrm{~mm}$ and corresponding \% dimensional deviation can be calculated using Eq. 5

$$
\begin{aligned}
& \% \text { Dimensiona deviation } \\
& =\frac{\text { Actual dimension }- \text { Measured dimension }}{\text { Actual dimension }} \times 10
\end{aligned}
$$

\section{Experimental results and discussion}

This section has two sub-sections. The first sub-section discusses the result of Taguchi methods experiments briefly. In second sub-section, on the results of application of GRA, Fig. 4 shows combined approach used for optimization of WEDM process.

\section{Effect of process parameters on MRR}

In order to see the effect of process parameters on the MRR, experiments were conducted using L9 OA (Table 2). The experimental data and $\mathrm{S} / \mathrm{N}$ ratios are given in Table 3. According to response in Table 4, graphs were generated. Figure 5 shows that the MRR increases with the increase of pulse on time and peak current, and decreases with increase in pulse off time. The phenomenon of effects of wire speed on MRR is different from another three parameters, here for second level, MRR is maximum but after that 


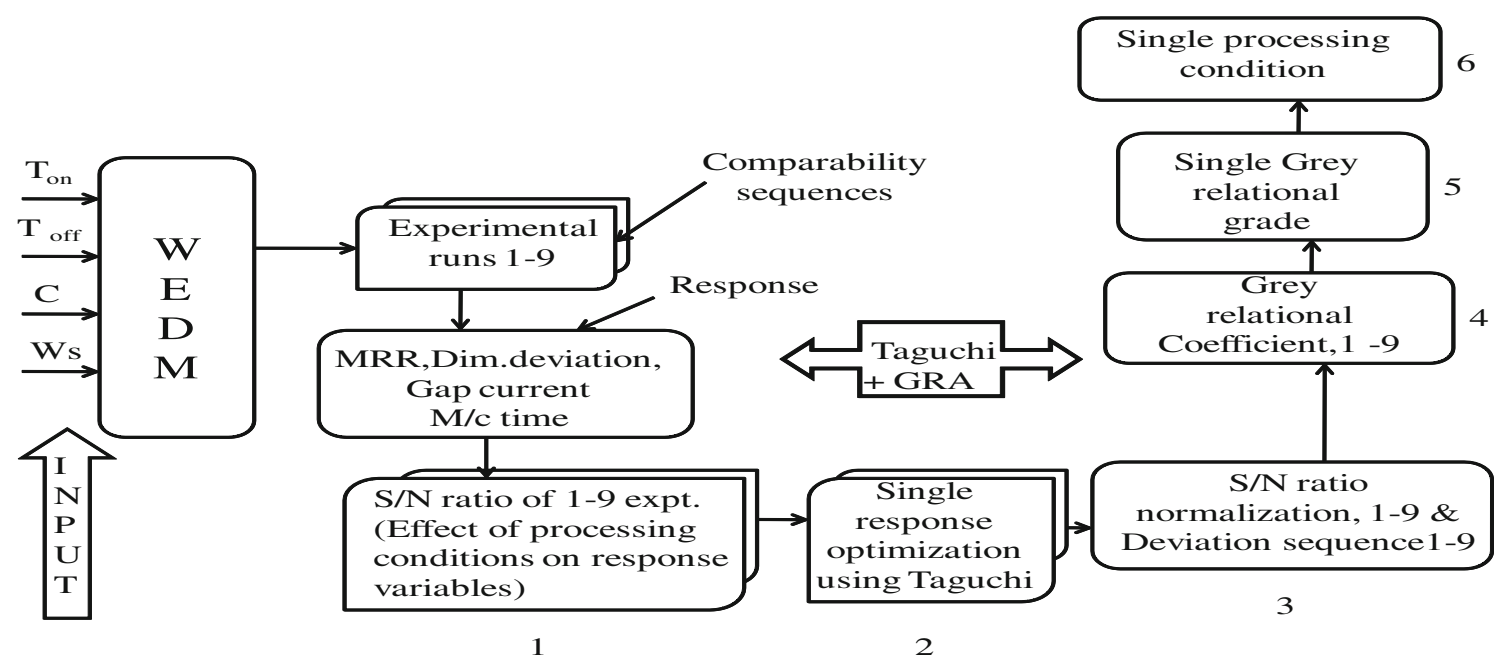

Fig. 4 Approach used for optimization of WEDM process

Table 3 Mean values and S/N ratios of observed results

\begin{tabular}{|c|c|c|c|c|c|c|c|c|}
\hline \multirow[t]{2}{*}{ Ortho. array } & \multicolumn{4}{|c|}{ Raw data } & \multicolumn{4}{|c|}{ Signal to noise ratios (DB) } \\
\hline & MRR & $\begin{array}{l}\text { Dim. } \\
\text { deviation }\end{array}$ & $\begin{array}{l}\text { Gap } \\
\text { current }\end{array}$ & $\begin{array}{l}\mathrm{M} / \mathrm{C} \\
\text { time }\end{array}$ & MRR & $\begin{array}{l}\text { Dim. } \\
\text { deviation }\end{array}$ & $\begin{array}{l}\text { Gap } \\
\text { current }\end{array}$ & $\begin{array}{l}\mathrm{M} / \mathrm{C} \\
\text { time }\end{array}$ \\
\hline 1 & 17.7 & 1.655 & 0.5 & 135.62 & 24.96 & -4.38 & -6.021 & -42.65 \\
\hline 2 & 28.6 & 1.667 & 1.3 & 83.98 & 29.13 & -4.437 & 2.279 & -38.48 \\
\hline 3 & 29.5 & 1.825 & 1.4 & 81.37 & 29.40 & -5.225 & 2.923 & -38.21 \\
\hline 4 & 38.4 & 1.742 & 1.7 & 62.51 & 31.69 & -4.819 & 4.609 & -35.92 \\
\hline 5 & 40.1 & 1.697 & 2.0 & 59.86 & 32.06 & -4.592 & 6.021 & -35.54 \\
\hline 6 & 21.1 & 1.595 & 0.6 & 113.84 & 26.49 & -4.055 & -4.437 & -41.13 \\
\hline 7 & 59.5 & 1.708 & 2.2 & 40.34 & 35.49 & -4.651 & 6.848 & -32.12 \\
\hline 8 & 22.2 & 1.672 & 0.7 & 108.12 & 26.93 & -4.463 & -3.098 & -40.68 \\
\hline 9 & 36.4 & 1.702 & 1.7 & 65.94 & 31.22 & -4.617 & 4.609 & -36.38 \\
\hline
\end{tabular}

Table 4 Response table for MRR (S/N Data) and raw data

\begin{tabular}{lllllllll}
\hline Levels & $\begin{array}{l}\text { Pulse on } \\
\text { time }\left(T_{\text {on }}\right)\end{array}$ & $\begin{array}{l}\text { Pulse off } \\
\text { time }\left(T_{\text {off }}\right)\end{array}$ & $\begin{array}{l}\text { Peak } \\
\text { current } \\
\left(I_{\mathrm{p}}\right)\end{array}$ & $\begin{array}{l}\text { Wire } \\
\text { speed } \\
(\mathrm{Ws})\end{array}$ & $\begin{array}{l}\text { Pulse on } \\
\text { time }\left(T_{\text {on }}\right)\end{array}$ & $\begin{array}{l}\text { Pulse off } \\
\text { time }\left(T_{\text {off }}\right)\end{array}$ & $\begin{array}{l}\text { Peak } \\
\text { current } \\
\left(I_{\mathrm{p}}\right)\end{array}$ & $\begin{array}{l}\text { Wire } \\
\text { speed } \\
(\text { Ws })\end{array}$ \\
\hline 1 & 27.83 & 30.71 & 30.71 & 29.41 & 25.27 & 38.53 & 20.33 & 31.40 \\
2 & 30.08 & 29.37 & 29.37 & 30.37 & 33.20 & 30.30 & 34.47 & 36.40 \\
3 & 31.21 & 29.03 & 29.03 & 29.34 & 39.37 & 29.00 & 43.03 & 30.05 \\
Delta & 3.39 & 1.68 & 1.68 & 1.03 & 14.10 & 9.53 & 22.70 & 6.37 \\
Rank & 2 & 3 & 3 & 4 & 2 & 3 & 1 & 4 \\
\hline
\end{tabular}

maximum wire speed insufficient time of sparking which reduce MRR.

Selection of optimal levels

In order to study the significance of the process variables towards MRR, analysis of variance was performed (Appendix: A). From these tables, it is clear that pulse on time, pulse off time, peak current and wire speed significantly affect both the MRR values. The ranks and the delta values show that current has the greatest effect on MRR and is followed by pulse on time, peak current, pulse off time and wire speed in that order. As MRR is the "higher the better" type quality characteristic, it can be seen from Fig. 5 that the third level of pulse on time (A3), first level of pulse off time (B1),third level of peak current (C3) and second level of wire speed (D2) provide maximum value of MRR. The $\mathrm{S} / \mathrm{N}$ data analysis suggests the 
Fig. 5 Effects of process parameters on MRR (S/N Data) and raw data

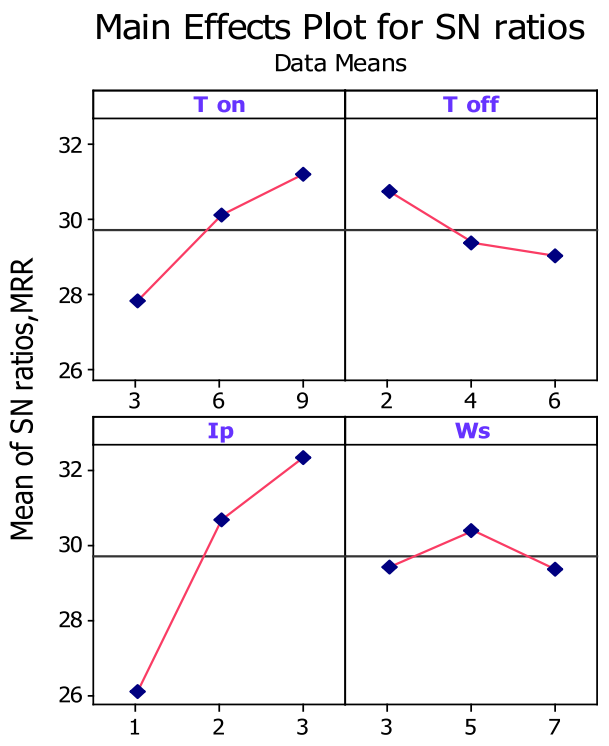

Signal-to-noise: Larger is better
Main Effects Plot for Means

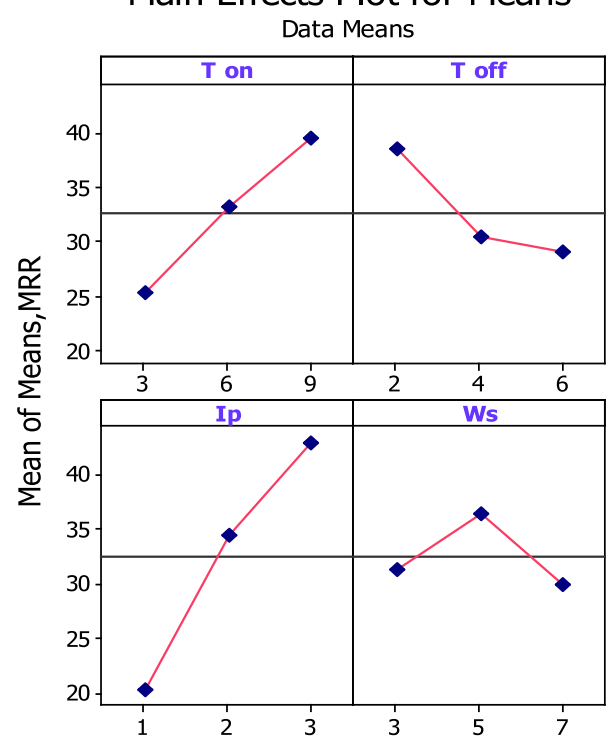

Table 5 Response table for dimensional deviation ( $\mathrm{S} / \mathrm{N}$ Data) and raw data

\begin{tabular}{lccllllll}
\hline Levels & $\begin{array}{l}\text { Pulse on } \\
\text { time }\left(T_{\mathrm{on}}\right)\end{array}$ & $\begin{array}{l}\text { Pulse off } \\
\text { Time }\left(T_{\text {off }}\right)\end{array}$ & $\begin{array}{l}\text { Peak } \\
\text { current } \\
\left(I_{\mathrm{p}}\right)\end{array}$ & $\begin{array}{l}\text { Wire } \\
\text { speed } \\
(\mathrm{Ws})\end{array}$ & $\begin{array}{l}\text { Pulse on } \\
\text { time }\left(T_{\mathrm{on}}\right)\end{array}$ & $\begin{array}{l}\text { Pulse off } \\
\text { time }\left(T_{\text {off }}\right)\end{array}$ & $\begin{array}{l}\text { Peak } \\
\text { current } \\
\left(I_{\mathrm{p}}\right)\end{array}$ & $\begin{array}{l}\text { Wire } \\
\text { speed } \\
(\mathrm{Ws})\end{array}$ \\
\hline 1 & -4.679 & -4.616 & -4.298 & -4.537 & 1.716 & 1.702 & 1.641 & 1.686 \\
2 & -4.489 & -4.497 & -4.633 & -4.381 & 1.678 & 1.678 & 1.705 & 1.657 \\
3 & -4.586 & -4.641 & -4.823 & -4.836 & 1.696 & 1.709 & 1.743 & 1.746 \\
Delta & 0.191 & 0.144 & 0.525 & 0.455 & 0.038 & 0.031 & 0.103 & 0.089 \\
Rank & 3 & 4 & 1 & 2 & 3 & 4 & 1 & 2 \\
\hline
\end{tabular}

same levels of the variables (A3, B1, C3, and D2) as the best levels for maximum MRR in WEDM process.

Effect of process parameters on dimensional deviation

The experimental data for dimensional deviation are given in Table 3. As per response Table 5 of mean and $\mathrm{S} / \mathrm{N}$ ratio, Fig. 6 show that dimensional deviation first decreases strongly with increase in pulse on time and then increases. As pulse off time increases, the dimensional deviation first decreases and then value of dimensional deviation is almost constant. With the increase in peak current, decrement in the value of dimensional deviation is observed. The effect of wire speed is very clearly seen. Dimensional deviation first decreases and then increases from level two to three, because fresh wire comes in contact with cutting zone which rapidly increases material erosion.

\section{Selection of optimal levels}

In order to study the significance of the process variables towards dimensional deviation, ANOVA was performed. It was found that the wire feed are most significant process parameters for dimensional deviation as compared to pulse on and pulse off time. The ranks and the delta values for various parameters show that wire speed has the greatest effect on dimensional deviation and is followed by current, pulse on time and pulse off time in that order. As dimensional deviation is the "lower the better" type quality characteristic, from Fig. 6, highest $\mathrm{S} / \mathrm{N}$ ratio corresponds to, second level of pulse on time (A2), second level of pulse off time (B2), first level of current (C1) and second level of wire speed (D2) provide minimum value of dimensional deviation. The $\mathrm{S} / \mathrm{N}$ data analysis (Fig. 6) also suggests the same levels of the variables (A2, B2, C1, and D2) as the best levels for minimum dimensional deviation in WEDM process.

\section{Effect of process parameters on gap current}

The experimental data of gap current are given in Table 3. According to the response Table 6 of S/N and mean value, Fig. 7 indicate the gap current increases with increase in pulse on time and peak current decreases with increase in pulse off time and wire speed is not influencing the gap current significantly. 
Fig. 6 Effects of process parameters on dimensional deviation (S/N Data) and raw data

Table 6 Response table for gap current (S/N Data) and raw data

Table 7 Response table for machining time (S/N Data) and raw data
Main Effects Plot for SN ratios

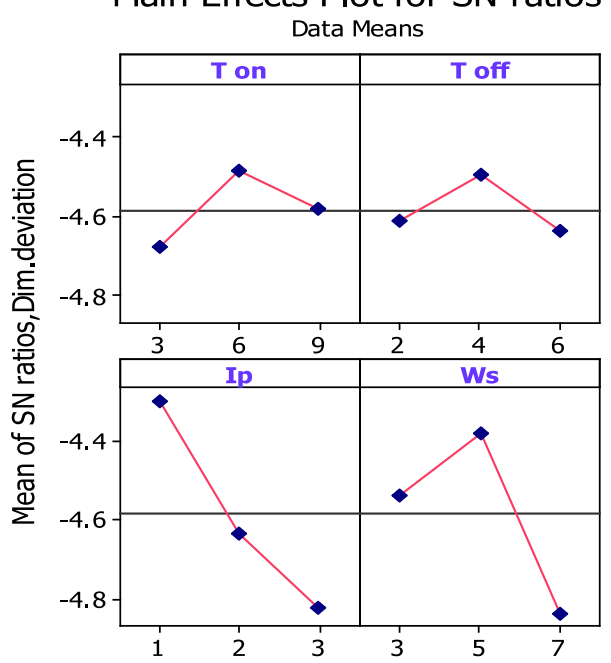

Signal-to-noise: Smaller is better
Main Effects Plot for Means Data Means

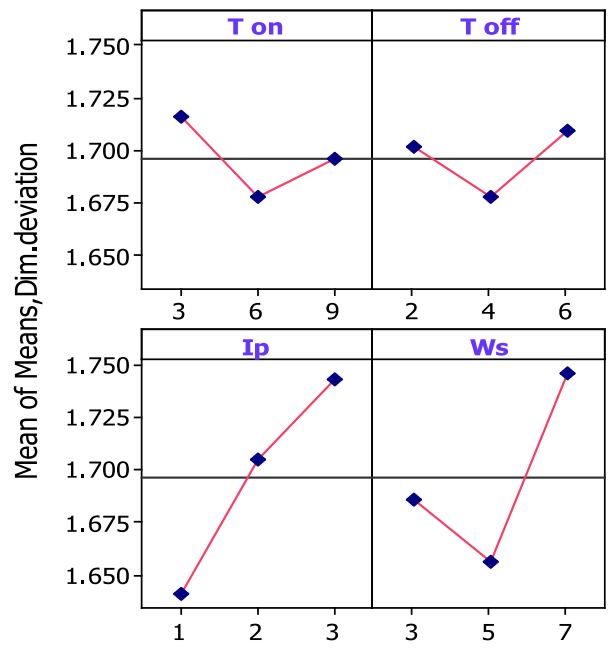

\begin{tabular}{lllllllll}
\hline Levels & $\begin{array}{l}\text { Pulse on } \\
\text { time }\left(T_{\text {on }}\right)\end{array}$ & $\begin{array}{l}\text { Pulse off } \\
\text { time }\left(T_{\text {off }}\right)\end{array}$ & $\begin{array}{l}\text { Peak } \\
\text { current } \\
\left(I_{\mathrm{p}}\right)\end{array}$ & $\begin{array}{l}\text { Wire } \\
\text { speed } \\
(\mathrm{Ws})\end{array}$ & $\begin{array}{l}\text { Pulse on } \\
\text { time }\left(T_{\text {on }}\right)\end{array}$ & $\begin{array}{l}\text { Pulse off } \\
\text { time }\left(T_{\text {off }}\right)\end{array}$ & $\begin{array}{l}\text { Peak } \\
\text { current } \\
I_{\mathrm{p}}\end{array}$ & $\begin{array}{l}\text { Wire } \\
\text { speed } \\
(\mathrm{Ws})\end{array}$ \\
\hline 1 & -0.2731 & 1.8123 & -4.5185 & 1.5363 & 1.0667 & 1.4667 & 0.6000 & 1.4000 \\
2 & 2.0642 & 1.7338 & 3.8323 & 1.5634 & 1.4333 & 1.3333 & 1.5667 & 1.3667 \\
3 & 2.7865 & 1.0315 & 5.2639 & 1.4778 & 1.5333 & 1.2333 & 1.8667 & 1.2667 \\
Delta & 3.0595 & 0.7808 & 9.7824 & 0.0856 & 0.4667 & 0.2333 & 1.2667 & 0.1333 \\
Rank & 2 & 3 & 1 & 4 & 2 & 3 & 1 & 4 \\
\hline
\end{tabular}

\begin{tabular}{lcccccccc}
\hline Levels & $\begin{array}{l}\text { Pulse on } \\
\text { time }\left(T_{\text {on }}\right)\end{array}$ & $\begin{array}{l}\text { Pulse off } \\
\text { time }\left(T_{\text {off }}\right)\end{array}$ & $\begin{array}{l}\text { Peak } \\
\text { current } \\
\left(I_{\mathrm{p}}\right)\end{array}$ & $\begin{array}{l}\text { Wire } \\
\text { speed } \\
(\mathrm{Ws})\end{array}$ & $\begin{array}{l}\text { Pulse on } \\
\text { time }\left(T_{\text {on }}\right)\end{array}$ & $\begin{array}{l}\text { Pulse off } \\
\text { time }\left(T_{\text {off }}\right)\end{array}$ & $\begin{array}{l}\text { Peak } \\
\text { current } \\
\left(I_{\mathrm{p}}\right)\end{array}$ & $\begin{array}{l}\text { Wire } \\
\text { speed } \\
(\mathrm{Ws})\end{array}$ \\
\hline 1 & -39.78 & -36.89 & -41.48 & -38.19 & 100.32 & 79.49 & 119.19 & 87.14 \\
2 & -37.53 & -38.23 & -36.93 & -37.24 & 78.74 & 83.99 & 70.81 & 79.39 \\
3 & -36.39 & -38.57 & -35.29 & -38.27 & 71.47 & 87.05 & 60.52 & 84.00 \\
Delta & 3.39 & 1.68 & 6.19 & 1.03 & 28.85 & 7.56 & 58.67 & 7.75 \\
Rank & 2 & 3 & 1 & 4 & 2 & 3 & 1 & 4 \\
\hline
\end{tabular}

Selection of optimal levels

To study the significance of the process variables towards gap current, ANOVA was performed (Appendix: 1). It was found that wire feed are non significant process parameter for gap current and it is observed that pulse on time, pulse off time and peak current significantly affect both the mean and the variation in the gap current values. The ranks and the delta values for various show that pulse on time has the greatest effect on gap current and is followed by pulse off time and peak current in that order. As gap current is the "larger the better" type quality characteristic, from Fig. 7, it can be seen that the third level of pulse on time (A3), first level of pulse off time (B1) and third level of peak current (C3), provide maximum value of gap current. The $\mathrm{S} / \mathrm{N}$ data analysis (Fig. 5) also suggests the same levels of the variables (A3, B1, and C3) as the best levels for maximum gap current in WEDM process.

Effect of process parameters on machining time

The experimental data of machining time are given in Table 3. As per response Table 7, Fig. 8 shows that the machining time reduces with the increase of pulse on time and peak current and decreases with increase in pulse off time. The phenomenon of effects of wire speed on 
Fig. 7 Effects of process parameters on gap current (S/N Data) and raw data
Main Effects Plot for SN ratios Data Means

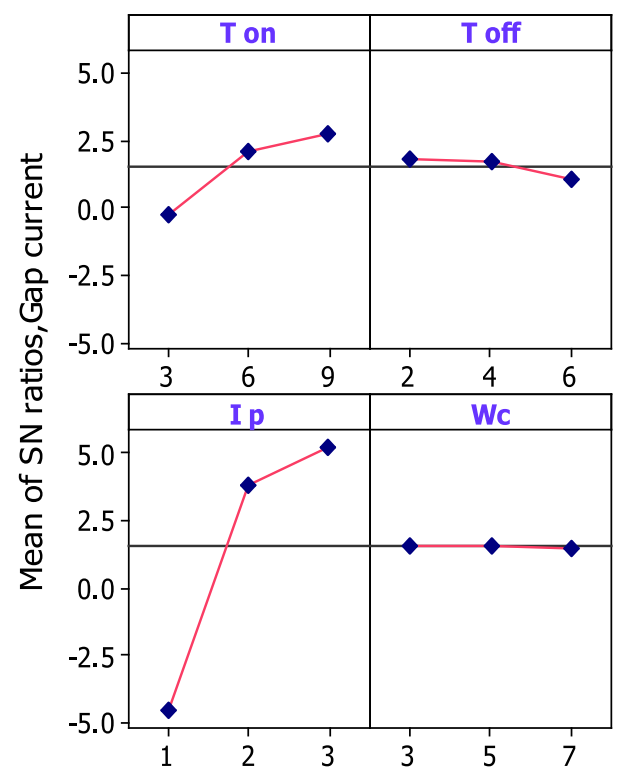

Signal-to-noise: Larger is better
Main Effects Plot for Means Data Means

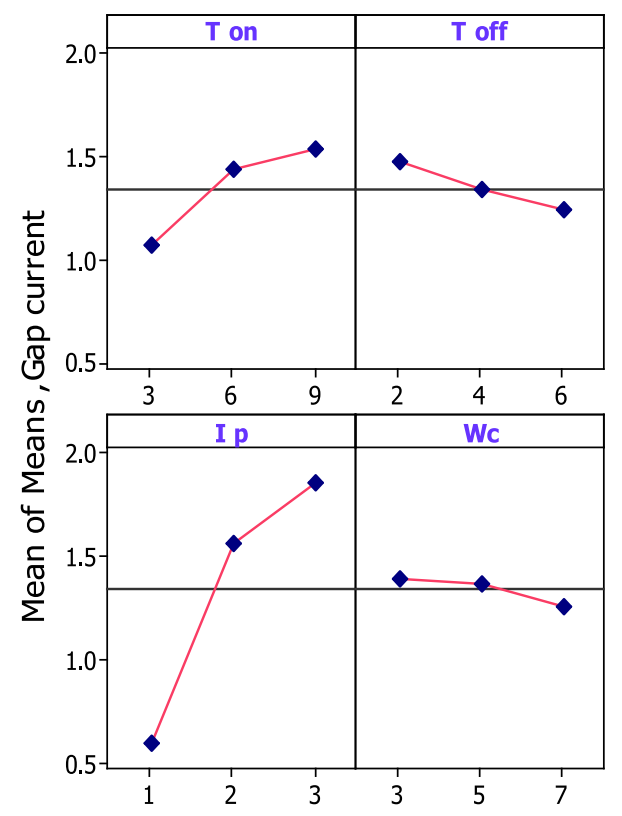

machining time is different from other three parameters, here for second level, cutting speed is maximum which reduces machining time but after that because of insufficient time of sparking at level No. 3, cutting speed is reduced therefore machining time increases.

\section{Selection of optimal levels}

In order to study the significance of the process variables towards machining time, ANOVA was performed. From these tables (Appendix: 1), it is clear that pulse on time, pulse off time, peak current and wire speed significantly affect both the machining time values. The ranks and the delta values show that current has the greatest effect on machining time and is followed by pulse on time, peak current, pulse off time and wire speed in that order. As machining time is the "Smaller is better" type quality characteristic, it can be seen from Fig. 8 that the third level of pulse on time (A3), first level of pulse off time (B1), third level of peak current (C3) and second level of wire speed (D2) provide less value of machining time. The $\mathrm{S} / \mathrm{N}$ data analysis (Fig. 6) also suggests the same levels of the variables (A3, B1, C3, and D2) as the best levels for minimizing machining time in WEDM process.

Estimation of optimum response characteristics

The optimal value of each response characteristic is predicted considering the effect of all parameter or most significant parameter. The estimated mean of the response characteristic can be determined using Eq. 6 (Ross 2005).

$\eta_{\mathrm{opt}}=\eta_{\mathrm{m}}+\sum_{i=4}^{q}\left(\eta_{i}-\eta_{\mathrm{m}}\right)$

where

$\eta_{\text {opt }}$ is the total mean of the machining characteristic under consideration,

$\eta_{\mathrm{m}}$ is the mean value at the optimum level (from response Tables) and $q$ is the number of process that significantly affects on machining characteristics.

For MRR, the optimum value is predicted at the optimal levels of significant variables which have already been selected as pulse on time (A3), pulse off time (B1), current (C3) and wire speed (D2). Therefore estimated mean of the MRR can be determined using Eq. 6

$$
\begin{aligned}
\eta_{\mathrm{opt}}= & 32.61+(39.37-32.61)+(38.53-32.61) \\
& +(43.03-32.61)+(36.40-32.61) \\
\eta_{\mathrm{opt}}= & 59.5 \mathrm{~mm}^{2} / \mathrm{min}
\end{aligned}
$$

For other three responses, predicted values were found using same fashion and corresponding experimental value displayed in Table 8.

\section{Multi-objective characteristics optimization}

In order to optimize the MRR, Dimensional deviation, gap current and machining time simultaneously GRA is used. 
Fig. 8 Effects of process parameters on $\mathrm{M} / \mathrm{C}$ time $(\mathrm{S} / \mathrm{N}$ Data) and raw data
Main Effects Plot for SN ratios Data Means

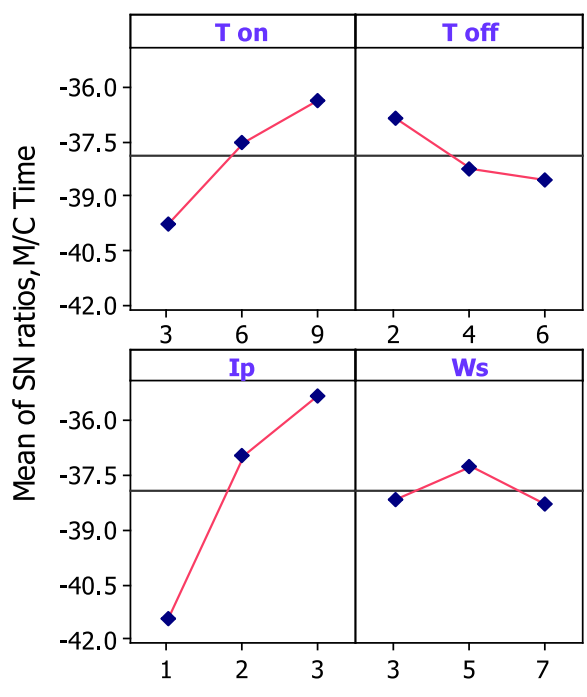

Signal-to-noise: Smaller is better
Main Effects Plot for Means

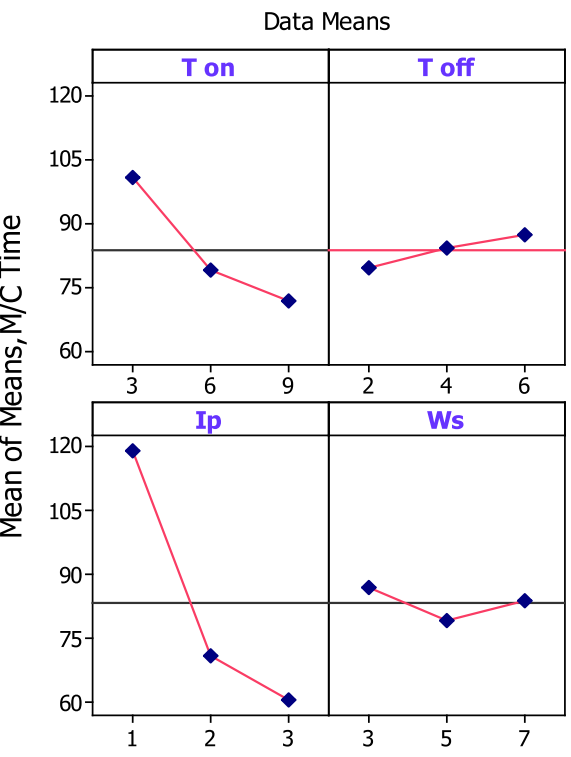

Table 8 Optimal value of individual machining characteristics

\begin{tabular}{lllll}
\hline $\begin{array}{l}\text { Sr. } \\
\text { no. }\end{array}$ & $\begin{array}{l}\text { Machining } \\
\text { characteristics }\end{array}$ & $\begin{array}{l}\text { Optimal } \\
\text { combination }\end{array}$ & $\begin{array}{l}\text { Predicted } \\
\text { optimal value }\end{array}$ & $\begin{array}{l}\text { Experimental } \\
\text { value }\end{array}$ \\
\hline 1 & MRR & A3B1C3D2 & $\begin{array}{c}59.5 \mathrm{~mm}^{2} / \\
\text { min }\end{array}$ & $\begin{array}{c}59.5 \mathrm{~mm}^{2} / \\
\min \end{array}$ \\
2 & $\begin{array}{c}\text { Dimensional } \\
\text { deviation }\end{array}$ & A2B2C1D2 & $1.56 \%$ & $1.69 \%$ \\
3 & $\begin{array}{c}\text { Gap current } \\
4\end{array}$ & A3B1C3 & $1.17 \mathrm{~A}$ & $1.2 \mathrm{~A}$ \\
& Machining & A3B1C3D2 & $40.34 \mathrm{~min}$ & $40.34 \mathrm{~min}$ \\
\hline
\end{tabular}

The following stepwise procedure of GRA optimization is used to solve the current formulation (Deng 1989).

\section{Normalization of $S / N$ ratio}

It is the first step in the GRA; a normalization of the $\mathrm{S} / \mathrm{N}$ ratio (Table 9) is performed to prepare raw data for the analysis where the original sequence is transferred to a comparable sequence. Linear normalizations are usually required since the range and unit in one data sequence may differ from the others. A linear normalization of the $\mathrm{S} / \mathrm{N}$ ratio in the range between zero and unity is also called as the grey relational generation. The "Larger is better" and "smaller-the-better" is a characteristic of the original sequence, and it is used to compare levels here in the GRA. Then, the original sequence should be normalized using Eqs. 7 and 8 .

1. Larger is better

$x_{i}^{*}(k)=\frac{x_{i}^{0}(k)-\min x_{i}^{0}(k)}{\max x_{i}^{0}(k)-\min x_{i}^{0}(k)}$
Table 9 Sequence after data pre-processing

\begin{tabular}{lclll}
\hline Ex. no. & MRR & $\begin{array}{l}\text { Dimensional } \\
\text { deviation }\end{array}$ & $\begin{array}{l}\text { Gap } \\
\text { current }\end{array}$ & $\begin{array}{l}\text { Machining } \\
\text { time }\end{array}$ \\
\hline $\begin{array}{l}\text { Ref. sequence } \\
\text { Comparability sequence }\end{array}$ & 1.0000 & 1.0000 & 1.0000 & 1.0000 \\
1 & 0.0000 & 0.2741 & 0.0000 & 1.0000 \\
2 & 0.3958 & 0.3263 & 0.6449 & 0.6047 \\
3 & 0.4213 & 1.0000 & 0.6949 & 0.5787 \\
4 & 0.6388 & 0.6530 & 0.8260 & 0.3612 \\
5 & 0.6745 & 0.4587 & 0.9357 & 0.3254 \\
6 & 0.1449 & 0.0000 & 0.1231 & 0.8556 \\
7 & 1.0000 & 0.5096 & 1.0000 & 0.0000 \\
8 & 0.1868 & 0.3485 & 0.2271 & 0.8131 \\
9 & 0.5947 & 0.4806 & 0.8260 & 0.4053 \\
\hline
\end{tabular}

2. smaller-the-better

$x_{i}^{*}(k)=\frac{\max x_{i}^{0}(\mathrm{k})-\mathrm{x}_{\mathrm{i}}^{0}(\mathrm{k})}{\max x_{i}^{0}(k)-\min x_{i}^{0}(k)}$

\section{Determination of deviation sequence}

The deviation sequence $\Delta_{o i}(k)$ is the absolute difference between the reference sequence $x_{i}^{0}(k)$ and the comparability sequence $x_{i}^{*}(k)$ after normalization. It is determined using Eq. 9.

$\Delta_{o i}(k)=\left|x_{0}^{*}(k)-x_{i}^{*}(k)\right|$

Calculation of grey relational coefficient (GRC)

GRC for all the sequences expresses the relationship between the ideal (best) and actual normalized $\mathrm{S} / \mathrm{N}$ ratio. If 
Table 10 The deviation sequences, Grey relational coefficients and grade values

\begin{tabular}{|c|c|c|c|c|c|c|c|c|c|c|c|}
\hline \multicolumn{5}{|l|}{ Deviation sequences } & \multicolumn{7}{|c|}{ Grey relational coefficients (GRC) and grade values } \\
\hline Deviation sequence & $\Delta_{01}(01)$ & $\Delta_{01}(02)$ & $\Delta_{01}(03)$ & $\Delta_{01}(04)$ & $\begin{array}{l}\text { Compa } \\
\text { sq. }\end{array}$ & MRR & $\begin{array}{l}\text { Dim. } \\
\text { deviation }\end{array}$ & $\begin{array}{l}\text { Gap } \\
\text { current }\end{array}$ & $\begin{array}{l}\mathrm{M} / \mathrm{C} \\
\text { time }\end{array}$ & $\begin{array}{l}\text { Grade } \\
\text { value }\end{array}$ & Rank \\
\hline No.1, $\mathrm{i}=1$ & 1.0000 & 0.7259 & 1.0000 & 0.0000 & 1 & 0.33333 & 0.4079 & 0.3333 & 1.0000 & 0.5186 & 6 \\
\hline No. $2, \mathrm{i}=2$ & 0.6042 & 0.6737 & 0.3551 & 0.3953 & 2 & 0.45281 & 0.4260 & 0.5847 & 0.5585 & 0.5055 & 7 \\
\hline No. $3, i=3$ & 0.5787 & 0.0000 & 0.3051 & 0.4213 & 3 & 0.46353 & 1.0000 & 0.6211 & 0.5427 & 0.6568 & 2 \\
\hline No. $4, \mathrm{i}=4$ & 0.3612 & 0.3470 & 0.1740 & 0.6388 & 4 & 0.58059 & 0.5903 & 0.7418 & 0.4391 & 0.5880 & 4 \\
\hline No. $5, \mathrm{i}=5$ & 0.3255 & 0.5413 & 0.0643 & 0.6746 & 5 & 0.60572 & 0.4802 & 0.8860 & 0.4257 & 0.5994 & 3 \\
\hline No.6, $i=6$ & 0.8551 & 1.0000 & 0.8769 & 0.1444 & 6 & 0.36898 & 0.3333 & 0.3631 & 0.7759 & 0.4603 & 9 \\
\hline No.7, $i=7$ & 0.0000 & 0.4904 & 0.0000 & 1.0000 & 7 & 1.00000 & 0.5048 & 1.0000 & 0.3333 & 0.7095 & 1 \\
\hline No. $8, i=8$ & 0.8132 & 0.6515 & 0.7729 & 0.1869 & 8 & 0.38076 & 0.4342 & 0.3928 & 0.7279 & 0.4839 & 8 \\
\hline No.9, $\mathrm{i}=9$ & 0.4053 & 0.5194 & 0.1740 & 0.5947 & 9 & 0.55229 & 0.4905 & 0.7418 & 0.4567 & 0.5603 & 5 \\
\hline
\end{tabular}

the two sequences agree at all points, then their GRC is 1. The GRC can be expressed by Eq. 10.

$\gamma_{0, i}(k)=\frac{\Delta_{\min }+\xi . \Delta_{\max }}{\Delta_{0 i}(k)+\xi . \Delta_{\max }}$

where,

$\Delta_{\min }=\min \cdot \min \Delta_{0, i}(k)$

$\Delta_{\max }=\max \cdot \max \Delta_{0, i}(k)$

$\Delta_{0 i}(k)$ is the deviation sequence and $\xi=$ distinguishing coefficient, $\xi \in(0,1)$ and $\xi$ is set as 0.5 in this study (Dabade 2013).

Investigating the data presented in Table 10 of deviation sequence, we can find that $\triangle(k)$ and $\Delta_{\min }(k)$ are as follows:

$\Delta_{\max }=\Delta o_{1}(1)=\Delta o_{6}(2)=\Delta o_{1}(3)=\Delta_{07}(4)=1.0000$

$\Delta_{\min }=\Delta o_{7}(1)=\Delta o_{3}(2)=\Delta o_{7}(3)=\Delta o_{1}(4)=0.0000$

\section{Determination of grey relational grade $(G R G)$}

The overall evaluation of the multi-objective characteristics is based on the grey relational grade. The grey relational grade is an average sum of the grey relational coefficients which is defined using Eq. 11.

$\gamma\left(x_{0}, x_{i}\right)=\frac{1}{m} \sum_{i=1}^{m} \gamma\left(x_{0}(k), x_{i}(k)\right)$

where, $\gamma\left(x_{0}, x_{i}\right)$ is the grey relational grade for the $j$ th experiment and $m$ is the number of performance characteristics.

\section{Analysis of GRG and selection of optimal level of parameters}

ANOVA has been performed using statistical software MINITAB 16 of Grey relational grade values to evaluate
Table 11 Response table for grey relational grade (GRG)

\begin{tabular}{lllll}
\hline Levels & $\begin{array}{l}\text { Pulse on } \\
\text { time }\left(T_{\text {on }}\right)\end{array}$ & $\begin{array}{l}\text { Pulse off } \\
\text { time }\left(T_{\text {off }}\right)\end{array}$ & $\begin{array}{l}\text { Peak } \\
\text { current }\left(I_{\mathrm{p}}\right)\end{array}$ & $\begin{array}{l}\text { Wire } \\
\text { speed }(\mathrm{Ws})\end{array}$ \\
\hline 1 & 0.5603 & 0.6054 & 0.4876 & 0.5595 \\
2 & 0.5492 & 0.5296 & 0.5513 & 0.5585 \\
3 & 0.5846 & 0.5592 & 0.6553 & 0.5762 \\
Max-Min & 0.0354 & 0.0758 & 0.1676 & 0.0175 \\
Ranking & 3 & 2 & 1 & 4 \\
\multicolumn{7}{l}{ Total mean value of GRG is 0.5647} & & \\
\hline
\end{tabular}

Table 12 Predicted and experimental values

\begin{tabular}{lllll}
\hline $\begin{array}{l}\text { Sr. } \\
\text { no. }\end{array}$ & $\begin{array}{l}\text { Machining } \\
\text { characteristics }\end{array}$ & $\begin{array}{l}\text { Initial } \\
\text { setting }\end{array}$ & $\begin{array}{l}\text { Predicted } \\
\text { value }\end{array}$ & $\begin{array}{l}\text { Experimental } \\
\text { value }\end{array}$ \\
\hline 1 & $\begin{array}{c}\text { Optimal } \\
\text { parameter }\end{array}$ & A3B1C3D2 & A3B1C3D3 & A3B1C3D3 \\
2 & $\begin{array}{c}\text { MRR }\left(\mathrm{mm}^{2} / \mathrm{min}\right) \\
\text { Dimensional } \\
\text { deviation \% }\end{array}$ & 59.5 & 57.9 \\
4 & $\begin{array}{c}\text { Gap current (A) } \\
5\end{array}$ & $\begin{array}{c}\text { Machining time } \\
\text { (min) }\end{array}$ & 40.34 & 1.73 \\
6 & $\begin{array}{c}\text { Grey relational } \\
\text { grade }\end{array}$ & 0.7095 & 0.7274 \\
7 & Improvement in grey relational grade $=1.22 \%$ \\
\hline
\end{tabular}

the influence of process parameters on multi-objective characteristics. ANOVA for grade values (Appendix: 1) shows that all four parameters, pulse on time (A), pulse off time (B), current (C) and wire speed (D) significantly affect the multi-objective characteristics under $95 \%$ confidence levels. It is clearly observed from Table 10 for grey 
relational grade that the process parameter "setting of experiment No. 7" has the highest grey relational grade $(0.7095)$ thus the seventh number experiment gives the best multiple performance characteristics among the nine experiments.

Using Taguchi method, response table has been generated (Table 11) to separate out the effect of each level of process parameters on grey relational grade as shown in Table 10. Basically, larger the grey relational grade, better the corresponding multi-objective characteristics. From the response Table 11, for grey relational grade, the best combination of the process parameters is set with A3B1C3D3.

\section{Prediction of grey relational grade under optimum parameters}

After evaluating the optimal parameter settings, the next step is to predict and verify the improvement of quality characteristics using the optimal parametric combination. The optimal grey relational grade $\left(\eta_{\text {opt }}\right)$ is predicted using Eq. 6 as described below:

$$
\begin{aligned}
\eta_{\mathrm{opt}}= & 0.5647+(0.5846-0.5647)+(0.6054-0.5647) \\
& +(0.6553-0.5647)+(0.5762-0.5647) \\
\eta_{\mathrm{opt}}= & 0.7274
\end{aligned}
$$

By using optimum combination A3B1C3D3, validation experiments were performed and corresponding values were displayed in Table 12. This value indicates that there is improvement in Grey Relational grade from 0.7095 to 0.7222 i.e., a total of $1.22 \%$ process is improved.

\section{Conclusions}

A TGRA was proposed to study the optimization of WEDM process parameters. MRR, Dimensional deviation, Gap current and machining time were selected as quality targets. Twenty-seven experimental runs based on OA were performed. The conclusions based on the single optimization and multi-optimization using TGRA are summarized as follows:

1. Experimental results of WEDM of D3 tool steel indicate current and pulse on time have significant effect on MRR and Gap current. Pulse on time and current have direct relation with MRR and Gap current but there is an inverse relation Machining time and them. Apart from these parameters, Current and wire speed have major contribution on dimensional deviation value because wire speed increases, fresh wire comes in contact with cutting zone which rapidly increases material erosion which causes dimensional deviation. Optimum combinations and corresponding value are show in Table 8.

2. Using GRA, Initial setting (A3B1C3D2) grade i.e., 0.7095 increases by using new optimum combination A3B1C3D3 up to 0.7218 means there is increment in grade of $1.22 \%$, Therefore, using present approach process parameters have been successfully optimized for better machining characteristics.

Acknowledgments The author would like to thank Dr. Kamal Jangra (Assistant Professor, PEC University of Technology, Chandigarh) and all those who contributed direct or indirectly.

Open Access This article is distributed under the terms of the Creative Commons Attribution License which permits any use, distribution, and reproduction in any medium, provided the original author(s) and the source are credited. 


\section{Appendix}

See Appendix Table 13.

Table 13 ANOVA tables for MRR, dimensional deviation, gap current, machining time and GRG

\begin{tabular}{|c|c|c|c|c|c|}
\hline Parameter & DOF & Seq. sum of square & Adj.sum of square & Adj. Mean square & $\%$ Contribution $(\mathrm{P})$ \\
\hline \multicolumn{6}{|c|}{ ANOVA for MRR } \\
\hline Pulse on time & 2 & 17.814 & 17.814 & 8.907 & 20.64 \\
\hline Pulse off time & 2 & 4.723 & 4.723 & 2.361 & 5.47 \\
\hline Peak current & 2 & 61.774 & 61.774 & 30.887 & 71.59 \\
\hline Wire speed & 2 & 1.977 & 1.977 & 0.9885 & 2.30 \\
\hline Total & 8 & 86.288 & & & \\
\hline \multicolumn{6}{|c|}{ ANOVA for dimensional deviation } \\
\hline Pulse on time & 2 & 0.05449 & 0.05449 & 0.02724 & 6.53 \\
\hline Pulse off time & 2 & 0.03533 & 0.03533 & 0.01767 & 4.23 \\
\hline Peak current & 2 & 0.42371 & 0.42371 & 0.21185 & 50.81 \\
\hline Wire speed & 2 & 0.32029 & 0.32029 & 0.16014 & 38.41 \\
\hline Total & 8 & 0.83382 & & & \\
\hline \multicolumn{6}{|c|}{ ANOVA for gap current } \\
\hline Pulse on time & 2 & 15.345 & 15.345 & 7.673 & 8.34 \\
\hline Pulse off time & 2 & 1.109 & 1.109 & 0.554 & 0.60 \\
\hline Peak current & 2 & 167.481 & 167.481 & 83.741 & 91.03 \\
\hline Wire speed & 2 & 0.011 & 0.011 & 0.006 & 0.005 \\
\hline Total & 8 & 183.947 & & & \\
\hline \multicolumn{6}{|c|}{ ANOVA for machining time } \\
\hline Pulse on time & 2 & 17.833 & 17.833 & 8.916 & 20.65 \\
\hline Pulse off time & 2 & 4.732 & 4.732 & 2.366 & 5.48 \\
\hline Peak current & 2 & 61.811 & 61.811 & 30.905 & 71.59 \\
\hline Wire speed & 2 & 1.962 & 1.962 & 0.981 & 2.27 \\
\hline Total & 8 & 86.338 & & & \\
\hline \multicolumn{6}{|c|}{ ANOVA for Grey relational grade (GRG) } \\
\hline Pulse on time & 2 & 0.0030415 & 0.0030415 & 0.0015208 & 4.76 \\
\hline Pulse off time & 2 & 0.0099166 & 0.0099166 & 0.0049583 & 15.52 \\
\hline Peak current & 2 & 0.0494332 & 0.0494332 & 0.0247166 & 77.38 \\
\hline Wire speed & 2 & 0.0014865 & 0.0014865 & 0.0007433 & 2.32 \\
\hline Total & 8 & 0.0638779 & & & \\
\hline
\end{tabular}

\section{References}

Ahmad R, Derman M, Marzuki M (2001) Primary study on machinability of aluminum matrix composite uses WEDM. Int J Eng Technol 10(06):145-150

Chiang KT, Chang FP (2006) Optimization of the WEDM process of particle-reinforced material with multiple performance characteristics using grey relational analysis. J Mater Process Technol 180:96-101

Dabade UA (2013) "Multi-objective process optimization to improve surface integrity on turned surface of $\mathrm{Al} / \mathrm{SiCp}$ metal matrix composites using grey relational analysis", Forty sixth CIRP Conference on Manufacturing System, 299-304

Datta S, Mahapatra SS (2010) Modeling, simulation and parametric optimization of wire EDM process using response surface methodology coupled with grey-Taguchi technique. Int J Eng Sci Techol 2(5):162-183
Deng J (1989) Introduction to grey system. J Grey Sys 1:1-24

Durairaja M, Sudharsun D, Swamynathan N (2013) Analysis of process parameters in wire edm with stainless steel using single objective Taguchi method and multi objective grey relational grade. Int Conf Design Manuf 64:868-877

Hewidy MS, El-Taweel TA, El-Safty MF (2005) Modeling the machining parameters of wire electrical discharge machining of Inconel 601 using RSM. J Mat Proces Technol 169:328-336

Jangra K, Grover S, Aggarwal A (2011) Simultaneous optimization of MRR and surface roughness for WEDM of WC-Co composite using grey relational analysis along with Taguchi method. Int $\mathrm{J}$ Ind Eng Comput 2:479-490

Jangra K, Grover S, Aggarwal A (2012) Optimization of multi machining characteristics in WEDM of WC-5.3 \% Co composite using integrated approach of Taguchi, GRA and entropy method. Front Mech Eng 7(3):288-299 
Kalpakjian S, Schmid SR (2009) Manufacturing process for engineering materials. Pearson education, South Asia

Kumar A, Kumar V, Kumar J (2013) Multi-response optimization of process parameters based on response surface methodology for pure Titanium using WEDM process. Int $\mathbf{J}$ Adv Manuf Technol 68:2645-2668

Liao YS, Huang JT, Su HC (1997) A study on the machining parameters optimization of wire electrical discharge machining. J Mat Process Technol 71:487-493

Mahapatra SS, Patnaik A (2006) Optimization of wire electrical discharge machining (WEDM) Process parameter using Genetic algorithm. Int J Eng Mat Sci 13:494-502

Muthu KV, Suresh BA, Suresh BA, Venkatasamy R, Raajenthiren M (2011) Process optimization of wire-EDM parameters by grey relational analysis based Taguchi method, vol 3. BITS, Pilani, pp 1-11

Phadke MS (2012) Quality engineering using robust design. Pearson Education, South Asia

Ramakrishnan R, Karunamoorthy L (2006) Multi response optimization of wire EDM operations using robust design of experiments. Int J Adv Manuf Technol 29:105-112

Rao RV (2011) Advanced modeling and optimization of manufacturing process. Springer Verlag London limited, London

Rao RV, Pawar PJ (2009) Modeling and optimization of process parameters of wire electrical discharge machining. J Eng Manuf 223(11):1431-1440
Ross PJ (2005) “Taguchi technique for quality engineering”, Tata McGraw-Hill Edition

Sarkar S, Mitra S, Bhattacharyya B (2005) Parametric analysis and optimization of wire electrical discharge machining of $\gamma$ Titanium Aluminide alloy. J Mater Process Technol 159:286-294

Shandilya P, Jain PK, Jain NK (2011) Modeling and analysis of surface roughness in WEDC of $\mathrm{SiC}_{\mathrm{P}} / 6061 \mathrm{Al} \mathrm{MMC}$ through Response Surface Methodology. Int J Eng Sci Technol 3(1):531-535

Sharma N, Khanna R, Gupta R (2013) Multi Quality Characteristics of WEDM Process Parameters with RSM. Int Confer Design Manuf IConDM 64:710-719

Shivade A, Shinde V (2013) A review on advanced multi-optimization methods for WEDM. Int $J$ Sci Res Eng Technol 2(7):435-439

Singh H, Garg R (2009) Effects of process parameters on MRR in WEDM. J Achiev Mat Manuf Eng 32(1):70-74

Taguchi G, Chowdhury S, Wu Y (2005) Taguchi's quality engineering handbook. Wiley, USA

Tosun N (2003) The Effect of the cutting parameters on performance of WEDM. KSME Int J 17:816-824

Tosun N (2006) Determination of optimum parameters for multiperformance characteristics in drilling by using grey relational analysis. Int J Adv Manuf Technol 28:450-455 